\title{
In-situ analysis of benthic \\ foraminifera by LA-ICPMS and its indication for coastal marine pollution
}

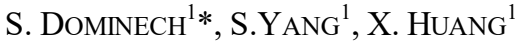 \\ ${ }^{1}$ School of Ocean and Earth Science, State Key Laboratory of \\ Marine Geology, Tongii University, Shanghai 200092, \\ China (*correspondence: dominech@tongji.edu.cn)
}

In the last decade, the laser ablation-inductively coupled plasma-mass spectrometry (LA-ICPMS) has been widely used on both benthic and planktonic foraminifera in paleoclimatic and paleoenvironmental fields. Guo et al. [1] have been able to identify hypoxia stages and Eggins et al. [2] used it to assess the paleo-seawater temperatures. Despite benthic foraminifera is regarded as bioaccumulator of heavy metals [3], few studies attempt to estimate the pollution history through LA-ICP-MS in-situ analysis. The big advantage of using the ablation technique on foraminifera is due to the possibility to spot on each growth chamber, in order to reconstruct high-resolution chemical intra-test variations [4], in foraminifera's lifetime ranges.

We analyze the heavy metal concentrations in benthic foraminifera collected at different depths in the Changjiang (Yangtze) estuarine and coastal marine sediments. The comparison among samples related to periods pre-, sin- and post-industrial development gave us important new insights into the pollution history of the area that has been subject to strong human activities in the large Changjiang catchment and estuary as well. In addition, a statistical assessment of the main differences and similarities between foraminifera and sediment chemistry can also better investigate the biogeochemical cycle of heavy metals. Innovatively, we prepared the samples in epoxy resin discs, which has two big advantages. Firstly, the flat surface of the resin discs let us avoid laser focusing problem, a critical source of uncertainty for any tridimensional sample analysed by LA-ICPMS. Secondly, we can obtain reliable environmental signals and avoid contamination due to chemical coating or secondary minerals formed during the early diagenesis stage.

The preliminary results are very promising and this novel technique will be widely used for monitoring the quality of the coastal marine environment.

[1] Guo et al. (2019) Geochim. Cosmochim. Acta, 245, 290-303. [2] Eggins et al. (2003) Earth Planet. Sci. Lett., 212, 291-306. [3] Suokhrie et al. (2017) Micropaleontol. its Appl., 265-284. [4] Hathorne et al. (2003) Geochemistry, Geophys. Geosystems, 4. 